\title{
ALERGIA AL LATEX EN LOS TRABAJADORES SANITARIOS (I). VIGILANCIA DE LA SALUD
}

\author{
MARÍA SOLEDAD GIL MICHARET*, FRANCISCO JOSÉ BARRIGA MEDINA*, \\ JOSÉ ANTONIO PÉREZ DE VILLAR GRANDE*
}

(*) Médico Especialista en Medicina del Trabajo. Unidad Básica de Prevención de Badajoz. Servicio de Prevención de Riesgos Laborales del Servicio Extremeño de Salud.

\section{RESUMEN}

La alergia al látex constituye un importante problema de salud entre los trabajadores sanitarios, tanto por su elevada prevalencia como por la gravedad de las reacciones que puede producir.

La detección temprana de los síntomas mediante una vigilancia de la salud específica, y las medidas encaminadas a evitar la sensibilización y a prevenir la aparición de sintomatología y la progresión de la enfermedad en los trabajadores ya sensibilizados, son las mejores estrategias de intervención sobre este problema ocupacional.

El artículo, realiza en esta primera parte, una revisión de la epidemiología, clínica y diagnóstico, y propone un protocolo médico específico.

\section{PALABRAS CLAVES}

Látex. Alergia. Trabajadores sanitarios. Vigilancia de la salud.

\section{ABSTRACT}

Latex allergy constitutes an important problem of health in the healthcare workers, so much for its high prevalence as for the graveness of the reactions that can take place.

The early detection of the symptoms by means of specific health surveillance, and the measures guided to avoid the sensitization and to prevent the symptomatology appearance and progression of the illness in the sensitized workers, are the best intervention strategies on this occupational problem.

The article carries out in this first part, a revision of the epidemiology, clinic and diagnosis, and it proposes a specific medical protocol.

\section{KEY WORDS}

Latex. Allergy. Healthcare workers. Health Surveillance. 


\section{J. A. PÉREZ DE VILLAR GRANDE}

\section{INTRODUCCION}

El látex es un líquido lechoso obtenido del árbol tropical Hevea brasiliensis o árbol del caucho. En su composición se encuentra la goma natural que es el polímero del 1-cis-4 poliisopropeno y que representa del $25 \%$ al $45 \%$; diversas proteínas representan del 1\% al 1,8\% del total, así como lípidos, carbohidratos, sustancias inorgánicas y agua ${ }^{(1)}$.

De los aproximadamente 240 polipéptidos presentes en el látex, alrededor de 60 son antigénicos y 13 de ellos han sido identificados, siendo el Hev b5 y el Hev b6 ${ }^{(2,3)}$ los alérgenos más frecuentemente involucrados en la sensibilización de los trabajadores sanitarios, mientras que en los niños afectados por malformaciones congénitas los alergenos más comunes son el Hev b1 y el Hev b3 ${ }^{(4,5)}$. Estas diferencias de sensibilización se deberían a la vía de contacto con el alérgeno, inhalatoria y de contacto con la piel en el caso de los trabajadores sanitarios y de contacto con las mucosas en los pacientes con espina bífida u otras malformaciones congénitas ${ }^{(6)}$. Hev b 6 y Hev b 11 parecen responsables de la mayor parte de las reacciones cruzadas entre el látex y algunas plantas y alimentos ${ }^{(7,8)}$.

Son proteínas solubles, que resisten la vulcanización, y en contacto con el sistema inmune promueven la estimulación apropiada para la síntesis de IgE específica y la aparición de reacciones de hipersensibilidad inmediata o Tipo I .

En la fabricación de objetos de goma, para aumentar su resistencia, elasticidad y durabilidad, al látex natural se le añaden diferentes sustancias. Entre estas sustancias destacan los aceleradores (grupos carbamato, tiuran, mercapto, guanidina, naftil y tiourea), y los antioxidantes (fenildiaminas) que son los agentes implicados con más frecuencia en la aparición de reacciones de hipersensibilidad retardada o Tipo IV (dermatitis de contacto alérgica). También se añaden pigmentos, cera insoluble, aceites y material de relleno ${ }^{(9)}$.

\section{EPIDEMIOLOGÍA}

Aunque la primera descripción de hipersensibilidad inmediata por látex se realiza en Alemania en $1927^{(10)}$ y en años posteriores se publican varios casos de urticaria de contacto con látex $(11,12,13,14,15,16)$. No es hasta la década de los 90 , coincidiendo con un incremento considerable de la prevalencia de la hipersensibilidad al látex y de reacciones anafilácticas intraoperatorias o durante exploraciones radiológicas (17), que se empieza a considerar un problema importante y a tomar medidas para paliarlo ${ }^{(18)}$.

En España, el primer caso de alergia inmediata al látex, publicado por Carrillo y col. en 1986, es el de una médico que presentó rinitis y urticaria-angioedema a los pocos minutos de utilizar guantes quirúrgicos, por lo que tras el estudio alergológico sugirieron que el alergeno podía ser una proteína presente en el látex natural ${ }^{(19)}$.

El aumento de la prevalencia de la alergia al látex se ha atribuido a: ${ }^{(20)}$

- El uso masivo de guantes a partir de la publicación de las Precauciones Universales y del uso del preservativo para la prevención de la transmisión del VIH ${ }^{(21)}$ y de otras enfermedades infecciosas.

- El aumento de la demanda de guantes que supuso un incremento de fabricantes, mayoritariamente en Asia y menos en Europa y Norte-América, que produjeron guantes de menor calidad y probablemente más alergénicos.

- Un mejor conocimiento y diagnóstico de la enfermedad.

En época reciente, algunos autores (Garabrant y col.) cuestionaron esta hipótesis; ellos piensan que los antecedentes personales de atopia desempeñan un papel fundamental ${ }^{(22)}$.

Los trabajadores sanitarios constituyen uno de los principales grupos de riesgo para el desarrollo de alergia al látex. La prevalencia de sensibilización al látex natural entre los profesionales sanitarios varía entre $7 \%$ y el $17 \%{ }^{(23)}$ frente al 1\% estimado para la población general, y la incidencia anual de sensibilización varía entre el $1 \%$ y el 2,5\% ${ }^{(24)}$.

El amplio rango de prevalencia encontrado puede deberse.

- A las diferencias de la población estudiada.

- Personal sintomático o asintomático.

- Categoría profesional y lugar de trabajo.

- A los métodos utilizados para determinar la sensibilización.

- Al país donde se realizó el estudio.

Se estima que una minoría del personal sanitario solicita la evaluación médica incluso teniendo sín- 
tomas, por ello, la verdadera prevalencia de estas reacciones entre el personal sanitario es descono$\operatorname{cida}^{(25)}$

El principal factor de riesgo en la producción de sensibilización o la inducción de reacción alérgica en el personal sanitario, es la exposición continuada a materiales compuestos de látex en el ámbito labo- ral. Cuando el sistema inmune se sensibiliza ya no existe un nivel de exposición al látex seguro y los trabajadores están en riesgo de sufrir reacciones alérgicas graves.

En el medio sanitario son numerosas las fuentes de exposición. Tabla 1

Tabla 1. Productos de uso sanitario que contienen o pueden contener látex

\begin{tabular}{|c|c|c|}
\hline Guantes & Compresores & Tubos de drenajes \\
\hline Tubos endotraqueales & Sondas vesicales y nasogástricas & Ambú \\
\hline Mascarillas & Esparadrapo & Almohadillas electrodos \\
\hline Sistemas de sueroterapia & Jeringas (émbolo) & Viales multidosis \\
\hline Tapones de goma & Cánulas & Colectores incontinencia \\
\hline Tubos endotraqueales & Apósitos adhesivos & Fonectores dental es \\
\hline y orofaríngeos & & Trócares de laparoscopia \\
\hline Empastes y diques dentales & Vendas elásticas & Productos desechables de papel \\
\hline Tetinas y chupetes & Ambú & (batas, mascarillas, salvacamas) \\
\hline Férula hinchables & Manguitos de esfigmomanómetros & \\
\hline
\end{tabular}

Varios factores se han relacionado con el aumento del riesgo de sensibilización al látex natural entre el personal sanitario ${ }^{(25)}$ :

- años de trabajo con exposición al riesgo.

- frecuencia o duración del uso de guantes.

- factores de riesgo individual: atopia, alergia a frutas (aguacate, kiwi, castañas, etc.), dermatitis previas, otras condiciones alérgicas (asma, eccema, alergias a otros alergenos, elevados niveles de IgE total, etc.).

\section{CLINICA}

La exposición a productos de látex puede desencadenar en el trabajador sanitario diferentes manifestaciones clínicas dependiendo del mecanismo patogénico implicado.

\section{Alergia al látex}

Los alergenos son proteínas solubles del látex que resisten la vulcanización y que en contacto con el sistema inmune promueven la estimulación apropiada para la síntesis de IgE específica y la aparición de reacciones de hipersensibilidad inmediata o Tipo $I$.

En el profesional sanitario la sensibilización se produce fundamentalmente por:

- Contacto con la piel.

- Inhalación, probablemente el principal mecanismo de sensibilización de los trabajadores sanitarios, en especial en áreas de trabajo en las que el uso frecuente de guantes provoca altas concentraciones de látex en el ambiente ${ }^{(26)}$. Las proteínas del látex se adhie- 
Tabla 2. Manifestaciones clínicas y mecanismo patogenético de la alergia al látex

\begin{tabular}{|c|l|}
\hline MECANISMO PATOGENETICO & MANIFESTACIONES CLINICAS \\
\hline \multirow{2}{*}{ Hipersensibilidad inmediata, Tipo I } & Urticaria \\
mediada por IgE & Angioedema \\
Rinoconjuntivitis \\
Asma bronquial \\
Hipersensibilidad retardada, Tipo IV mediada por & Anafilaxia \\
\cline { 2 - 2 } & Dermatitis de contacto \\
\hline células & \\
\hline No inmunológico & Dermatitis irritativa \\
\hline
\end{tabular}

ren al polvo utilizado como lubricante en los guantes y al usarlos, las partículas de polvo y el alergeno del látex se suspenden en el aire pudiendo ser inhalados.

La sintomatología es variable dependiendo de la susceptibilidad individual, de la vía de exposición, y la cantidad de alergeno contactado ${ }^{(27)}$ y aparece de forma inmediata, desde escasos minutos a una hora tras la exposición.

Los síntomas pueden ser:

- Cutáneos: Urticaria de contacto, eccema, prurito, angioedema.

- Respiratorios: Rinoconjuntivitis, Asma bronquial.

- Sistémicos: Shock anafiláctico.

La urticaria localizada en las manos por el uso de guantes de látex es el más común de los síntomas de alergia al látex en el personal sanitario, a menudo el único y también el inicial, progresando a otras manifestaciones si persiste la exposición ${ }^{(28)}$. Consiste en la aparición inmediata (generalmente minutos) de habones pruriginosos que desaparecen a los 3060 minutos de finalizado el contacto.

Otra manifestación clínica por contacto es el angioedema, caracterizado por tumefacción (edema) de la piel, mucosas y tejidos subcutáneos.
Las manifestaciones respiratorias son una de las formas más frecuentes de presentación en el personal sanitario. Se producen por inhalación de las partículas de látex suspendidas en el aire. Pueden presentarse aisladamente como resultado de la inhalación del alergeno o en el contexto de una reacción sistémica. La prevalencia de la rinoconjuntivitis ocupacional por exposición a guantes de látex se estima entre un $1,2 \%$ y un $16 \%$ y la de asma hasta de un $6,8 \%{ }^{(29)}$.

Las reacciones generalizadas suceden generalmente en actos quirúrgicos, donde el contacto con el material de látex es más íntimo y prolongado.

Síndrome Látex-Frutas: La sensibilización al látex puede manifestarse como alergia alimentaria por reactividad cruzada con frutas o verduras (plátano, aguacate, kiwi, tomate, patata cruda, castaña, melón, piña, higo, uva, col, naranja).

\section{Dermatitis alérgica de contacto (DCA)}

Está mediada por un mecanismo de hipersensibilidad retardada o Tipo IV. Los alergenos son los aditivos y aceleradores de la vulcanización, tales como tiuran, carbamatos, y derivados de benzotiazol, tiurea y aminas. De estos productos los que con mayor frecuencia producen sensibilización son los derivados del tiuran, seguidos de los carbamatos. No obstante el propio látex puede actuar por este 
mecanismo ${ }^{(9)}$. Se caracteriza por la aparición de un eccema en las zonas de contacto de aparición tardía en las 24-48 horas posteriores al contacto.

Este tipo de reacción puede ser eliminada en su totalidad si se identifica mediante pruebas epicutáneas el agente químico causante y se evita la exposición al mismo.

\section{Dermatitis de contacto imitativa}

La dermatitis irritativa de las manos es la manifestación cutánea más frecuente asociada al contacto con objetos de látex, sobre todo al uso de guantes. No está mediada por mecanismo inmunológico y se ve favorecida por la exposición a otros productos irritantes habituales en el ambiente sanitario, como el uso de jabones, detergentes, humedad mantenida. Tras contacto reiterado aparece eritema, prurito, descamación y vesículas. La atopia constituye un factor de riesgo para desarrollar dermatitis irritativa. Hay que tener en cuenta que la hipersensibilidad natural de los individuos atópicos incrementa su reactividad frente a irritantes, y esto, a su vez, puede aumentar el riesgo de sensibilizaciones debido a la pérdida de eficacia de la barrera dérmica ${ }^{(30)}$.

Estas reacciones se diagnostican tras haber excluido las reacciones mediadas por IgE, las más importantes, y las reacciones de hipersensibilidad retardada.

\section{Dermatitis proteica}

La cronificación de las lesiones de urticaria, mediada por una alergia tipo I a las proteínas del látex, puede dar lugar a una dermatitis proteica. Desde el punto de vista clínico cursa como una combinación de una alergia inmediata (tipo I) y una alergia tardía (tipo IV), caracterizándose por su cronicidad con episodios de intensa reagudización tras contactar el trabajador con sustancias de alto contenido proteico a las que se encuentra sensibilizado. Es muy difícil distinguirla de una dermatitis de contacto mediada por hipersensibilidad retardada (tipo IV) a los aditivos que se le añaden al látex en el proceso de fabricación ${ }^{(30)}$.

\section{VIGILANCIA DE LA SALUD}

En la evaluación médica inicial y en las evaluaciones periódicas de los trabajadores sanitarios se debe realizar un examen médico específico del riesgo. El objetivo es identificar a los trabajadores con mayor probabilidad de sensibilización; sintomatología sugestiva de alergia al látex; o ya diagnostica- dos, a fin de aplicar las medidas de protección necesarias para impedir la sensibilización en el primer caso; hacer un diagnóstico precoz en el segundo; y aplicar las medidas de prevención adecuadas para evitar los síntomas y la progresión de la enfermedad en caso de sensibilización confirmada.

\section{Examen médico específico}

\section{Historia laboral}

- Exposición actual

- Antigüedad en el puesto.

- Puesto de trabajo: descripción de tareas, equipos de protección individual utilizados, tolerancia a los mismos, condiciones ambientales del área de trabajo (ventilación, temperatura, etc.), exposición a otros productos sensibilizantes o irritantes etc.

- Tipo de exposición: Fuentes, usos, tiempo, vías.

- Exposición previa

- Trabajos anteriores.

- Años de exposición.

- Tipo de exposición: Fuentes, usos, tiempo, vías.

\section{Historia clínica}

- Antecedentes familiares

- Atopia.

- Alergias a medicamentos/alimentos.

- Urticarias/dermatitis.

- Asma Bronquial.

- Hábitos: Tabaco, alcohol y drogas de abuso principalmente inhaladas.

- Exposición extralaboral: jardinería, bricolaje, tareas domésticas etc..

- Antecedentes personales

- Dermatitis atópica.

- Alergias a alimentos (aguacate, kiwi, patata, tomate, plátano, etc.). Otras alergias.

- Intervenciones quirúrgicas múltiples.

- Reacciones adversas durante intervenciones diagnósticas o terapéuticas (dentista, ginecólogo).

- Espina bífida. 


\section{J. A. PÉREZ DE VILLAR GRANDE}

- Tolerancia previa a los guantes en casa o en el trabajo, a los globos, a los preservativos u otros productos elaborados con látex.

- Dermatitis de contacto alérgicas, irritativas o no filiadas.

- Afección dermatológica crónica diagnosticada sin relación con la actividad laboral.

- Rinitis/conjuntivitis.

- Asma bronquial.

- Infecciones respiratorias de repetición.

- Reflujo gastroesofágico.

- Anamnesis

Interrogar sobre la presencia de síntomas y/o lesiones dermatológicas (prurito, urticaria local, eccema, angioedema); oculares (prurito, enrojecimiento), respiratorios (prurito nasal, estornudos, rinorrea, obstrucción nasal, tos, sibilancias), en relación con el uso de guantes y/o con la exposición en áreas donde se utilizan habitualmente.

- Exploración física

- Dermatológica: Si existen lesiones descripción del tipo de lesión y localización de las mismas.

- Inspección ocular: eritema conjuntival, quemosis.

- Auscultación cardiopulmonar: alteración del ritmo cardíaco, sibilancias, roncus, disminución del murmullo.

- Pruebas complementarias específicas

\section{Pruebas IN VIVO}

\section{Pruebas cutáneas}

- Prick test o técnica de punción. Detecta la presencia de IgE específica frente al látex, localizada en la superficie de los mastocitos. Se considera el mejor método diagnóstico de la alergia al látex, con una alta sensibilidad, especificidad, valor predictivo positivo y negativo. La sensibilidad oscila entre el 54\% al 92\% dependiendo del tipo de extracto ${ }^{(28)}$. Algunos pacientes con pruebas cutáneas positivas no refieren síntomas tras exposición al látex, lo que se conoce como sensibilización subclínica.

- Pruebas epicutáneas o patch tests. Se utilizan para estudiar las reacciones de hipersensibili- dad retardada. Se parchean una serie estándar de sustancias químicas que incluyen los aditivos utilizados en el procesamiento del látex. Se puede probar el látex utilizando trozos del material problema (guante, preservativo, etc.) o incluso látex natutral.

\section{Pruebas de exposición o provocación cutánea.}

Indicadas cuando no existe correlación entre el resultado de las pruebas cutáneas y la historia clínica. Estas pruebas comportan riesgo y deben realizarse tan solo en medio hospitalario por personal cualificado.

- Test de uso. Consiste en colocar sobre la mano humedecida un dedo de guante de látex y mantenerlo 15 minutos; como control se coloca un guante de vinilo en la otra mano. La aparición de lesiones habonosas en la primera hora se considera una respuesta positiva. La sensibilidad es del $100 \%{ }^{(28)}$.

- La prueba de frotamiento (rubbing test). Consiste en frotar suavemente un guante de látex durante 30 segundos sobre la piel del antebrazo previamente humedecida y esperar la aparición de habones a intervalos de 15 minutos durante la hora siguiente.

Las pruebas de exposición conjuntival, nasal y bronquial no suelen emplearse de forma rutinaria.

\section{Pruebas IN VITRO}

\section{Determinación de IgE específica sérica}

Mediante técnica RAST, CAP o ALASTAT o con diferentes tipos ELISA. La principal ventaja de los métodos serológicos son su seguridad y comodidad, y los principales inconvenientes la menor sensibilidad y mayor coste que el prick test. La comparación de estos métodos con las pruebas cutáneas proporciona una sensibilidad del CAP del $86 \%$ y del ALASTAT del 84\%, con una especificidad variable en función de la población seleccionada ${ }^{(22)}$. La especificidad es baja, en especial en polínicos y alérgicos a frutas ${ }^{(31)}$.

Test de liberación de histamina.

Poco útil en la clínica diaria.

\section{Pautas de actuación}

1. Ausencia de factores de riesgo y de sintomatología sugestiva 
- Vigilancia de la salud con periodicidad en función del riesgo de exposición.

2. Ausencia de síntomas actuales o previos pero con presencia de factores de riesgo individual: atopia, alergia a frutas, eccema o lesiones dermatológicas previas etc.

- Medidas para reducir la exposición y otros factores de riesgo.

a. uso de guantes "NO LATEX" sin polvo.

b. Cuidado de las manos.

- Determinación de IgE total e IgE específica al látex. Si IgE positiva derivar a Alergólogo.

- Vigilancia de la salud con periodicidad en función del riesgo global (de exposición e individual) con determinación de IgE total e IgE específica al Látex.

\section{Presencia de manifestaciones clínicas actua- les o previas sugestivas de alergia al látex}

\subsection{Sospecha clínica}

- Determinar IgE total e IgE específica al látex.

- Espirometría si presenta sintomatología respiratoria.

- Derivación al Alergólogo para la realización de las pruebas complementarias diagnósticas específicas.
3.2 Diagnóstico de certeza

- Tratamiento:

- Evitar la exposición. Información al trabajador en relación a medidas de evitación laboral y extralaboral, materiales y productos que contienen o pueden contener látex natural.

- Inmunoterapia.Valoración individual. Prescripción por Alergólogo.

- Declaración de enfermedad profesional (32). Puede incluirse en:

Grupo 4 Agente H Subagente 01 ò 02 Actividad 23 ò $24^{\mathrm{a}}$.

Grupo 5 Agente B Subagente 01 Actividad 23 o $24^{\mathrm{b}}$.

- Solicitar la evaluación del riesgo de exposición en el puesto de trabajo y en función de la misma y de las características clínicas, establecer las medidas preventivas y de protección específicas.

- Información al empresario de la aptitud del trabajador para el desempeño del puesto de trabajo y de las medidas protección y prevención necesarias para la adaptación del puesto o propuesta de cambio de puesto.

(a) Grupo 4: Enfermedades profesionales causadas por inhalación de sustancias y agentes no comprendidos en otros apartados. Agente H: Sustancias de alto peso molecular (sustancias de origen vegetal, animal, microorganismos, y sustancias enzimáticas de origen vegetal, animal y/o de microorganismos) Subagente 01: rinoconjuntivitis. Subagente 02: Asma. Actividad: 23 Personal sanitario, 24 personal de laboratorios médicos y farmacéuticos.

(b) Grupo 5: Enfermedades profesionales de la piel causadas por sustancias y agentes no comprendidos en algunos de los otros apartados. Agente B Subagente 01: Agentes y sustancias de alto peso molecular, por encima de los 1000 daltons, (sustancias de origen vegetal, animales microorganismos, y sustancias enzimáticas de origen vegetal, animal y/o de microorganismos) Actividad: 23 Personal sanitario, 24 personal de laboratorios médicos y farmacéuticos. 


\section{BIBLIOGRAFÍA}

1. Quirce Gancedo S. Alergia al látex. Alergol Inmunol Clin 2000;15 Supl 1:89-96

2. Sutherland MF, Drew A, Rolland JM, Slater JE, Suphioglu C, O’Hehir RE. Specific monoclonal antibodies and human IgE show Hev b5 is an abundant allergen in high proteim powdered latex gloves. Clin Exp allergy 2002;32:583-9

3. Posch A, Chen Z, Raulf-Heimsoth M, Baur X. Latex allergens: review of current knodledge. Pneumologie 1997;51:1058-62

4. Czuppon AB, Chen Z, Rennert S, Engelke T, Meyer HE, Heber M, et al. The rubber elongation factor of rubber trees (Hevea brasiliensis) is the major allergen in latex. J Allergy Clin Immunol 1993;92:690- 7.

5. Wagner B, Buck D, Hafner C, Sowka S, Niggemann B, Scheiner O, et al. Hev b 7 is a Hevea brasiliensis protein associated with latex allergy in children with spina bifida. J Allergy Clin Immunol 2001;108:621- 7.

6. Dres.Claudio A. Parisi, Beatrice Biló, Floriano Bonifazzi, Sergio Bonini y José F. Máspero. Alergia al látex. Arch Argent Pediatr 2006; 104(6):520-529

7. Blanco C, Díaz Perales A, Collada C, SánchezMonge R, Aragoncillo C, Castillo R, Ortega N, Alvárez M, Carrillo T, Salcedo G. Class I chitinases as potential panallergens involved in the latex-fruit syndrome. J Allergy Clin Inmunol 1999;103: 507-513

8. Posch A, Wheeler CH, Chen Z, Flagge A, Dunn $\mathrm{MJ}$, et al. Class I endochitinase containing a hevein domain is the causative allergen in the latexassociated avocado allergy. Clin Exp Allergy 1999; 29:667-672

9. Ministerio de Sanidad y Consumo. Consejo Interterritorial del Sistema Nacional de Salud.

Comisión de Salud Pública. Protocolos de Vigilancia Sanitaria Específica. Dermatosis Laborales. 2003

10. Stern G, Uberempfindlichkeit gegen kaustchuk als urasche von. Urticaria und quickeschem odem. Klin Wochenschrift 1927;6:1096-7

11. Förström L. Contact urticaria from latex surgical gloves. Contact Dermatitis. 1980;6(1):33-4

12. Kleinhans D. Contact urticaria to rubber gloves. Contact Dermatitis 1984;10(2):124-5

13. Meding B, Fregert S. Contact urticaria from natural latex gloves. Contact Dermatitis 1984;10(1):52-3

14. Van der Meeren HLM, van Erp PE. Life threatening contact urticaria from gloves powder. Contact Dermatitis 1986;14(3):190-1
15. Van Ketel WG. Contact urticaria from rubber gloves after dermatitis from thiurams. Contact Dermatitis 1984;11(5):323-4

16. Frosch PJ, Wahl PJ, Bahmer FA, Maasch HJ. Contact urticaria to rubber gloves is IgE mediated. Contact Dermatitis 1986;14(4):241-5

17. Ownby DR, Tomlanovich M, Sammons N, McCullough J. Anaphylaxis associated with latex allergy during barium enema examinations. Am J Roentgenol 1991;156(5):903-8

18. Thompson RL. Educational challenges of latex protein allergy. In: Fink J, ed. Latex allergy. Filadelfia: Immunol allergy Clin North Am 1995;15:159-74

19. Carrillo T, Cuevas M, Muñoz T, Hinojosa M, Moneo J. Contact urticaria and rhinitis from latex surgical gloves. Contact Dermatitis 1986;15(2):69-72

20. Servicio Andaluz de Salud. Recomendaciones para la Prevención y tratamiento de la Alergia al Látex. 2004

21. Centers for Disease Control. Recommendations for Prevention of VIH transmision in health-care settings. MMWR 1987; 36 (Suppl 2): 1S-18S

22. Negro Alvárez JM, Miralles López JC, Pascual Camùs A, López Sánchez JD, Pagán Alemán JA, García Sellés FJ, Hernández García J. Alergia al Látex. Archivos de Alergia e Inmunología Clínica; 2003; 34;2; 28-35

23. New Jersey Departement of Health and Senior Services. Guidelines. Management of Natural Rubber Latex Allergy. Selecting the Right Glove for the Right Task in Health care Facilities.

24. Garabrant DH, Schweitzer S. Epidemiology of latex sensitization and allergies in health care workers. J Allergy Clin Immunol 2002; 110(Suppl 2):S82-95.

25. Elizabeth A. Bolyard, RN, MPH, Ofelia C. Tablan, MD,aWalter W. Williams, MD, Michele L. Pearson, MD, Craig N. Shapiro, MD, Scott D. Deitchman, $\mathrm{MD}$, and The Hospital Infection Control Practices Advisory Committee. Guideline for infection control in health care personnel 1998; 325-6.

26. Turjanmaa K, Mäkinen-Kiljunen S, Reunala T, Alenius H, Palosuo T. Natural rubber latex allergy; the European experience. En: Fink J, ed. Latex allergy. Filadelfia: Saunder. Inmunol Allergy Clin North Am 1995;15; 71-87

27. Slater JE. Latex allergy. En : Kay AB, ed. Allergy and allergic diseases. Oxford: Blackwell Science, 1997; 981-93 
28. De Gonzalo Garijo, A Sensibilización al látex. I Curso sobre la Actividad Sanitaria en los Servicios de Prevención. Consejería de Sanidad y Consumo Junta de Extremadura, 2001

29. Fish JE. Occupational asthma and rhinoconjunctivitis induced by natural rubber latex exposure. J Allergy Clin Immunol 2002; 110(Suppl 2):S75-81.

30. Anda M, Gómez B, Lasa E, Arroabarren E, Garrido S, Echechipía S. Alergia al látex. Manifestaciones clínicas en la población general y reactividad cruzada con alimentos Anales Sis San Navarra vol.26 suppl.2 Pamplona 2003
31. Díez-Gómez ML, Quince S, Cuevas M, Sánchez Fernández C, Baz G, Moradiellos FJ, et al. Fruit-pollenlatex cross-reactivity: implication of profilin. Allergy 1999;54 (9); 951-61

32. REAL DECRETO 1299/2006, de 10 de noviembre, por el que se aprueba el cuadro de enfermedades profesionales en el sistema de la Seguridad Social y se establecen criterios para su notificación y registro. 